\title{
IMPERATIVNE SLOŽENICE U ENGLESKOM I SRPSKOM JEZIKU
}

U ovom radu daje se komparativna analiza složenica koje imaju glagol u form i imperativa kao prvi dio složenice. Razmatra se njihova semantika i forma kao i ortografske karakteristike u engleskom i srpskom jeziku. Kao što je analiza pokazala, neke složenice ovog tipa imaju zajedničke formalno-semantičke karakteristike. Tako na primjer egzocentrične složenice u oba jezika imaju derogativno značenje kada upućuju na ljude, a neutralno kada upućuju na nežive referente. Egzocentrične složenice egzistiraju u strukturi predikat + objekat, a endocentrične u strukturi subjekat + predikat.

Ključne riječi: imperativne složenice, engleski jezik, srpski jezik.

\section{Uvodna razmatranja}

Složenice nastaju kao rezultat morfološkog slaganja dvije samostalne riječi. Jednu podvrstu složenica čine složenice u literaturi poznate kao imperativne složenice, odnosno glagolsko-objekatske složenice (Progovac 2006, Gast 2008) ili imeničke složenice sa glagolskim prvim dijelom (Barić 1980-81). Ono što ih čini zanimljivim je forma u kojoj se javljaju i značenje koje imaju. U engleskom jeziku se malo pažnje posvećivalo ovoj problematici (Bauer 1983, Plag 2003, Progovac 2006), što, prema riječima Gasta (2008: 270) odražava marginalnu poziciju koju glagolsko-objekatske složenice imaju u leksičko-gramatičkom sistemu engleskog jezika. U srpskom jeziku, problemom imperativnih složenica bavili su se Barić (1980-81), Stevanović (1988, 1989), Klajn (2002) i dr.

\footnotetext{
*_ jelena.sajinovic-novakovic@flf.unibl.org
} 
Imperativne složenice, kao što im samo ime kaže, u prvom dijelu imaju glagol u obliku imperativa, a u drugom imenicu u nominativu kao u kažiprst, razbibriga, ili u akuzativu kao u Derikonja (prezime). Pojedini lingvisti, kao Maretić (1899), osporavali su imperativno porijeklo značenja ovih imenica. Ovo osporavanje rezultat je činjenice da u velikom broju složenica ovog tipa oblik prezenta za treće lice i oblik imperativa imaju isti završetak (3.1.jedn on/mlati i oblik imperativa mlati). Ipak, kod jednog broja glagola postoji razlika između nastavka za imperativ i prezenta za treće lice kao kod složenice derikoža kod koje treće lice prezenta glasi dere, a ne deri. Ponekad prvi dio složenice ne odgovara ni prezentu za treće lice, ali ni obliku imperativa, kao kod složenice cjepidlaka. Prezent jednine za treće lice glasi cijepa, a oblik imperativa cijepaj. Pretvaranje nesvršenog u svršeni glagol moglo bi objasniti ovu pojavu. Ako se nesvršenom glagolu cepati doda prefiks pre-, onda precepi postaje obliki imperativa glagola precepiti (Progovac 2006: 5) - otuda oblik cepi u složenici cepidlaka, odnosno cjepidlaka u ijekavskoj varijanti.

Stevanović u svojoj knjizi Savremeni srpskohrvatski jezik I (1989: 413) iznosi argument koji ide u prilog imperativnoj prirodi ovih složenica kada kaže da imperativ „,pored modalnih ima i drugačije službe”, kao što je na primjer izražavanje pripovjedačkog imperativa koji opisuje repetitivne radnje koje su se pripisivale pojedincima koji su ih obavljali i prema kojima su dobijene osobine i izvedeni nazivi kakve imamo danas u pomenutim složenicama. Imperativ u ovim složenicama ima transpozicionalno značenje i ne označava zapovijest, zahtjev ili molbu (Lalić 2012: 140). Neke osobine su bile toliko učestale da su vremenom od izraza koji opisuje osobu prvo prešle u antroponim sa funkcijom nadimka, pa onda u prezimena. U korist njihovoj imperativnoj prirodi govori i sama činjenica da se njima izražava stav prema nekome ili nečemu. Iako u srpskom postoje riječi kojima se može opisati osoba koja pije kao pijanica, složenica ispičutura je snažnija, šaljivija, zabavnija, ekspresivnija (Progovac 2006: 6).

I u engleskom jeziku je dovođeno u pitanje imperativno porijeklo prvog dijela složenice, pa tako Bauer (1983) primjećuje da je ponekad teško odrediti da li je prvi dio imenica kod složenica kao leap year ili wash-day ili glagol, pošto prvi dio složenice postoji i u obliku glagola i u obliku imenice.

Složenice ovoga tipa Stevanović (1989: 412) svrstava u dopunske složenice kod kojih je dopuna bliži objekat upravnog glagola koji stoji u 
obliku imperativa. Među njima ima i složenica kod kojih je upravni član imenski, a determinativni je glagolski dio (Stevanović 1988: 186). One nisu nastale od glagolskog oblika i njegove objekatske dopune nego od imenice u službi subjekta i njegova predikata (Stevanović 1989 :412).

Imperativne složenice mogu biti endocentrične i egzocentrične. Kod egzocentričnih složenica upravna riječ se nalazi izvan same složenice (Plag 2002: 186), a ta njihova egzocentričnost se odnosi prvenstveno na semantiku, dok morfološke karakteristike nasleđuju od desnog člana složenice, što se odvija prema pravilu desnog centra. Egzocentrične složenice imaju preneseno značenje jer ne znače ono što pojedinačno označavaju dijelovi riječi od kojih su sastavljene. Na primjer gulikoža nije vrsta kože, niti onaj koji doslovno guli kožu, već u prenesenom značenju onaj koji vam debelo naplati za neku uslugu. Egzocentične glagolsko-imeničke složenice nisu produktivne u jeziku odraslih, ali su česta stategija koju koriste djeca za identifikovanje objekata ili osoba (Gast 2008: 279). Jedna studija iz 1986. godine (Clark, Hecht Mulford) je pokazala da je obrazac stvaranja složenih riječi po principu spajanja glagola i objekta blizak djeci u početnom stadiju korištenja jezika. Oko treće godine života djeca stvaraju složenice tipa 'grate-cheese' umjesto 'cheese grater' ili 'rip-paper' umjesto 'paper-ripper'.

U nekim ranijim radovima o imperativnim složenicama pominjane su i složenice koje u prvom dijelu imaju nadri-, laži-, nazovi-. Prema Barić (1980-81:24), ove riječi nisu dijelovi složenice nego prefiksi u značenju lažni, nepravi, tobožnji: nadribabica, nadrinaučnik, nadripjesnik, nadriumjetni, lažigaće, nazovipredsjednik, nazoviotac, nazoviliberal i sl, pa neće biti razmatrane u ovom radu.

\section{Metode i cilj}

U cilju prikazivanja formalno-semantičkih karakteristika imperativnih složenica u dva jezika, korištena je komparativna metoda. Prilikom prikupljanja korpusa korišteni su rječnici oba jezika i Gramatika reči, The Grammar of Words (1996). U okviru korpusa analizirano je 52 antroponima (50 u srpskom i 2 u engleskom), 12 zoonima ( 6 u srpskom i 6 u engleskom), 11 fitonima (3 u srpskom i 8 u engleskom), 45 složenica kojima se upućuje na ljude ( 25 u srpskom i 20 u engleskom), 94 složenice kojima se upućuje na predmete (4 u srpskom i 90 u engleskom) i 5 složenica kojima se upućuje na dječije igre u engleskom jeziku.Više podataka o izvorima nalazi se u spisku korištene literature. 


\section{Rezultati}

a) Rod

Gramatički rod većine složenica sa imperativom ima nastavke za ženski rod, iako se istim oblikom složenice upućuje na osobe muškog i ženskog pola. Na primjer, složenica prišipetlja se može odnositi na bilo koji rod koji prišiva petlju kome. Složenice probisvijet i vrtirep su muškog roda.

b)Egzocentrične složenice

Prema sintaksičkom odnosu njihovih sastavnih dijelova, većina egzocentričnih složenica se javlja u strukturi: predikat +objekat:

treadmill, scarecrow, punchball, killjoy, catchpenny; pazikuća, gaziblato, mutimir, razbibriga, probisvijet, gulikoža.

Mali broj složenica u engleskomjeziku ima formu: subjekat+ predikat:

turntable, crybaby, watchdog.

U pogledu ortografije u oba jezika najveći broj egzocentričnih složenica se piše kao jedna riječ: catchpenny, telltale, spendthrift, mamipara, tužibaba, raspikuća, a samo jedan mali broj složenica u engleskom jeziku se piše sa crticom: break-bottle, suck-egg, cut-throat.

Već je bilo riječi o porijeklu složenica ovog tipa koje su prvobitno nastale pretvaranjem neke repetitivne loše navike u izraz koji opisuje osobu. Zbog toga su ove složenice uglavnom emocionalno obojene sa derogativnim prenesenim značenjem osim složenica pazikuća i watchdog (kada se odnosi na osobu ili grupu ljudi):

vrtiguz, vrtirep, vucibatina, gladibrk, gulikoža, derikoža, mutikaša, raspikuća, sjecikesa, ližisahan, mutivoda, palikuća, pušimagla, cjepidlaka, probisvijet;

suck-egg, pickpocket, turncoat, spoilsport, killjoy, crybaby, telltale, spendthrift, hangdog, picktooth, rattlebrain, rattlehead.

Kod prezimena nastalih na ovaj način u srpskom jeziku, glagolski dio se kombinuje sa nekom od imena životinja kao vuk, koja je najčešća, 
zatim koza, krava, kučka ili dijelom tijela, uglavnom kosmatim, kao,brada, brk, kosa, imenicama kao kapa, voda, baka, koliba, kuća i sl: Beribaka, Berilaža, Vrtikapa, Gazibara, Gazivoda, Gorikapa, Delipara, Derikonja, Derikrava, Derikučka, Mažibrada, Mastikosa, Metikoš, Palibrk, Palikoliba, Palikuća, Palivoda, Pecikoza, Pirivatra, Pletikapa, Prodribaba, Pustivuk, Pušibrk, Stanivuk, Tolimir, Traživuk. Sve ove složenice su egzocentrične. I dok su prezimena u srpskom jeziku uglavnom pežorativnog ili pogrdnog značenja, imena izvedena od imperativa i imenice su pozitivna i predstavljaju vrstu optativa, odnosno želje da se glagolom ostvari označeno zbivanje ili stanje kroz osobu koja nosi određeno ime. Kod muških imena, glagoli se, u najvećem broju slučaja kombinuju sa imenicama mir i bor: Branimir, Budimir, Gostimir, Gradimir, Želimir, Zvonimir, Zlatibor/ Zlatimir, Kažimir, Krasimir, Krstimir, Milimir, Radimir, Slavimir, Stanimir, Hvalimir, Hranimir, dok se kod ženskih imena kombinuju samo s imenicom slava pa tako nastaju imena: Berislava, Borislava, Budislava, Svetislava, Stanislava, Hranislava. Jedini primjeri prezimena u engleskom jeziku kod kojih je prvi dio imperativ su Shakespeare i Turnpenny. Istorijski, prvo prezime potiče iz staroengleskog schak(k)en 'to brandish' (mahati/ vitlati čime, naročito oružjem) + speer 'spear'(koplje) i prvobitno se koristilo kao nadimak za osobe koje su agresivne i svadljive, ili koje su ženskaroši. A oblik imperativa u drugom prezimenu vjerovatno nikada nije imao funkciju imperativa i u ovom prezimenu se našao samo kao rezultat fonetskog zapisa jednog mjesta u Francuskoj. Jako rijetko se ovom vrstom složenica imenuju toponimi. Jedini zabilježeni primjeri su Palilula (beogradska opština) i Kill Devil (Grad u Sjevernoj Karolini).

Jedan dio egzocentričnih imperativnih složenica imenuje fitonime: ranilist, catchfly, i zoonime: letilist, letipas, gazivoda, suck-egg, wagtail. Imenica kao suck-egg, može da se odnosi na osobu (young, folish, contemptible), ali i na životinju poput pijetla ili lasice koji sisaju jaja.

Ova vrsta složenica koristi se i u nominaciji dječijih igara. Prema upravnoj riječi sve su egzocentrične iako ukazuju na postupak igranja tako naprimjer punchball nije vrsta lopte, niti je hug kid vrsta djeteta. Takve su još i složenice kickball, break-bottle, leapfrog.

U srpskom jeziku jako mali broj imperativnih složenica označava stvari ili nešto drugo od gore pomenutog, a taj se broj svodi na svega nekoliko složenica koje se javljaju sa glagolima vaditi, razbiti kao u vadičep i razbibriga. 
U engleskom jeziku, ovaj način imenovanja stvari je daleko produktivniji. Iako su uglavnom endocentrične, jedan manji broj ovakvih složenica je egzocentričan. Takve su složenice breakwater, treadmill, watchman, spitfire, scarecrow, catchpenny, turnscrew, turnpike.

\section{c) Endocentrične složenice}

Endocentrične imperativne složenice su one kod kojih je formalna upravna riječ ujedno i semantička upravna riječ. Prema sintaksičkom odnosu njihovih sastavnih dijelova, većina endocentričnih složenica u engleskom se može svrstati u tri grupe, od kojih prva i druga predstavljaju nešto češći način građena endocentričnih složenica:

subjekat+predikat $\rightarrow$ drip coffee, glow-warm, stinkweed, rattlesnake, popcorn, drift wood;

predikat+adverbijal $\rightarrow$ workbench, searchlight, springboard, grindstone, plaything;

predikat + objekat $\rightarrow$ drawbridge, punchbag, punchcard.

U srpskom jeziku, složenice ovog tipa prate prvi obrazac:

subjekat+predikat $\rightarrow$ skočidjevojka, plačidrug, smrdibuba

Kada je u pitanju ortografija ovih složenica, u engleskom jeziku su zabilježena tri načina zapisivanja. Najčešći način je da se pišu kao jedna riječ kao u punchbag, rattlesnake, flashlight. Drugi, nešto rjeđi način pisanja je odvojeno pisanje kao u rush hour, fick knife, search party. Samo mali broj složenica se piše sa crticom: glow-warm. U srpskom jeziku endocentrične složenice se uvijek pišu kao jedna riječ.

Iako smo već rekli da gotovo sve analizirane složenice koje opisuju osobine ljudi pripadaju klasi egzocentričnih složenica, složenica kao skočidjevojka zapravo opisuje djevojku. Postoji jedan broj endocentričnih složenica u engleskom jeziku kojima se upućuje na ljude i koje najčešće opisuju zanimanja ili stil života kao što je složenica playboy. Kod tih složenica drugi dio složenice je uglavnom hiponim sa komponentom mlad (boy↔man,girl $\leftrightarrow$ woman), call girl, pin up girl, call boy.

Endocentrične složenice u oba jezika su ograničene na nekoliko glagola i nekoliko imenica kada su u pitanju živi referenti iz klase zoonima i 
fitonima: skočiti, smrdjeti, strizati kod skočimiš, smrdibuba, strizibuba, i u engleskom glow, rattle, bumble, stink, cut kao u složenicama: glow-warm, rattlesnake, bumblebee, stinkweed, cutworm.

Endocentričnim imperativnim složenicama mogu se označavati i neživi referenti kao kažiprst i palidrvce. U engleskom jeziku ta lista složenica je duža i u njoj se pojavljuju glagoli poput punch, drift, search i imenice poput wood, ice, light, stone, bridge, knife, board, list:

punchcard, punchbag, drift wood, drift ice, driftweed, whetstone, grindstone, flashlight, searchlight, drawbridge, swing bridge, lift bridge, flick knife, draw knife, springboard, washboard, checklist, waitlist.

Jedan dio endocentričnih složenica u engleskom jeziku ima vremensku i mjesnu referencu. One koje u drugom dijelu složenice imaju sat/dan/ godinu označavaju vrijeme vršenja određene radnje: npr. dan kada se pere posteljina i odjeća, obično je to jedan određeni dan u sedmici, je washday. Godina koja preskače ustaljen način računanja dana u godini i ima dan viška je leap year. Dio dana kada se ljudi vraćaju sa posla ili idu na posao je rush hour, a dan isplate je pay day. Vrijeme za igru je playtime. Takva je složenica pamtivijek u srpskom, koja se javlja u izrazu od pamtivijeka. Složenice sa mjesnom referencijom upućuju na mjesto playground, watchtower, bakeshop. U američkoj varijanti engleskog jezika prvi dio složenice ukazuje na svrhu, a drugi je imenica room: restroom, washroom. Složenica ovog tipa nema među analiziranim primjerima u srpskom jeziku.

\section{Zaključak}

Imperativne složenice u engleskom i srpskom imaju neke zajedničke formalno-semantičke karakteristike. U oba jezika egzocentrične složenice se javljaju u obrascu predikat+objekat. Ova vrsta složenica se u engleskom piše na dva načina: kao jedna riječ ili sa crticom, što je karakteristično za mali broj primjera. U srpskom jeziku sve egzocentrične složenice se pišu kao jedna riječ. I u jednom i u drugom jeziku egzocentrične složenice su derogativne kada upućuju na osobe. U srpskom jeziku jedan broj antroponima (imena i prezimena) ima formu imperativne složenice u kojoj je prvi dio glagol sa značenjem paljenja (gori, pali, peci), deranja, pušenja, puzanja, a imenica zoonim (vuk, koza, krava) ili kosmati dio tijela (brada 
brk, kosa). U engleskom jeziku samo jedno prezime ima formu imperativne složenice i to je prezime Shakespeare. Lična imena u ovoj formi imaju značenje optativa, želje da se glagolom ostvari označeno stanje kroz osobu koja nosi određeno ime.U engleskom jeziku nema ličnih imena složenih od imperativa i imenice.

Osim što označavaju ljude u oba jezika, jedan broj složenica upućuje na biljke i životinje. U engleskom jeziku ovakav način imenovanja je produktivan u nazivima dječijih igara i nazivima neživih referenata.

Endocentrične imperativne složenice u oba jezika se javljaju u formi subjekat+ predikat, dok se u engleskom javljaju još i u formi predikat + objekat i predikat + adverbijal. U pogledu ortografije, postoje tri načina pisanja ovih složenica: kao jedna riječ, kao dvije riječi i sa crticom (jako mali broj primjera). U srpskom jeziku se sve endocentrične složenice pišu kao jedna riječ. U oba jezika, endocentrične složenice su ograničene na nekoliko glagola kada upućuju na žive referente. U srpskom jeziku jako mali broj složenica ovog tipa upućuje na nežive referente, dok je u engleskom ta lista duža i obuhvata glagole punch, drift, search i imenice wood, ice, light, stone, bridge, knife, board, list. Jedan broj endocentričnih imperativnih složenica ima vremensku i mjesnu referencu. U srpskom jeziku je zabilježena samo jedna složenica sa vremenskom referencom i nijedna sa mjesnom.

\section{LITERATURA}

Bauer, L. (1983). English Word-Formation. Cambridge: Cambridge University Press.

Barić, E. (1980-1981). Imeničke složenice sa glagolskim prvim dijelom. Rasprave, 6-7, 17-30.

Clark, E, B.F, Hechti R.C.Mulfor (1986). Coining Complex compounds in English: Affixes and Word Order in Acquisition. Lingusitics, 24, 7-29.

Gast,V.(2008). Verb-noun compounds in English and German, ZAA 269-282.

Lalić, M. (2012). Imenička tvorba u njemačkom i srpskom jeziku na primjeru ekspresivnih imenica sa značenjem lica. Riječ, nova serija broj 8, 130-147.

Maretić, T. (1899). Gramatika hrvatskoga jezika za niže razrede srednjih škola. Zagreb: Izdanje Kugli.

Maretić, T. (1899). Gramatika i stilistika hrvatskoga ili srpskoga književnog jezika. Zagreb: Kugli. 
Plag, I. (2002). Word-Formation in English. Cambridge: Cambridge University Press.

Progovac, Lj. (2006). Fossilized Imperative in Compounds and Other Impressions: Possible Implications for Historical and Evolutionary Studies, Online Proceedings of the First Meeting Slavic Lingusitic Society, Bloomington, IN, pristupljeno u novembru mjesecu 2020. godine, dostupno na:https:// www.researchgate.net/publication/228732520_Fossilized_Imperative in_Compounds_and_Other_Expressions_Possible_Implications_for_ Historical_and_Evolutionary_Studies

Stevanović, M. (1988). Od Vuka do Belića i dalje. Beograd: Zavod za udžbenike I nastavna sredstva.

Stevanović, M. (1989). Savremeni srpskohvatski jezik I. Uvod. Fonetika, Morfologija, peto izdanje. Beograd: Naučna knjiga.

\section{Izvori}

Klajn, I. i M. Šipka, (2008). Veliki rečnik stranih reči i izraza. Novi Sad: Prometej.

Longman Dictionary of Contemporary English, pristupano u novembru i decembru 2020. godine dostupno na:

https://www.ldoceonline.com/dictionary/glow-worm.

Milojević, J. (1996). Gramatika reči, The Gramar of words. Beograd: Matematički institut SANU, Filološki fakultet.

Petrović,V. i K. Dudić. (1989). Rečnik glagola sa gramatičkim i leksičkim dopunama. Beograd: Zavod za udžbenike i nastavna sredstva.

Rečnik srpskoga jezika (2011). (izradili MilicaVujanić i drugi, redigovao i uredio Miroslav Nikolić), izmenjeno i popravljeno izdanje, Novi Sad: Matica srpska.

Skok, P. (1971, 1972, 1973). Etimologijski rječnik hrvatskog ili srpskoga jezika. Zagreb: Jugoslovenska akademija znanosti i umjetnosti. 


\section{Jelena Šainović Novaković \\ Božana Tomić}

\section{IMPERATIVE COMPOUNDS IN ENGLISH AND SERBIAN}

\section{Summary}

This paper deals with a comparative analysis of compounds which have the imperative as their left-hand member. We discuss the semantics and form of these compounds and their orthographical characteristics in English and Serbian. As the analysis has shown, a number of compounds share some formal and semantic features in the two languages. Exocentric compounds in both languages are derogatory when referring to people, and neutral when referring to inanimate entities. Exocentric and endocentric compounds in two languages seem to take the same pattern, that of subject + predicate with endocentric compounds and that of predicate + object with exocentric compounds. Bearing in mind that the subject has not been extensively dealt with in comparative studies of English and Serbian, we believe that this paper will encourage further studies of this topic.

Key words: imperative compounds, English, Serbian 